\title{
Information System Strategy for Total Quality Management (TQM) in Aviation Industry
}

\author{
Saber Qasim \\ Department of Information Systems, \\ Faculty of Computing and Information Technology, \\ King Abdulaziz University, Jeddah \\ Kingdom of Saudi Arabia
}

\author{
Aasim Zafar \\ Department of Information Systems, \\ Faculty of Computing and Information Technology, \\ King Abdulaziz University, Jeddah \\ Kingdom of Saudi Arabia
}

\begin{abstract}
This study reflects on analyzing different types of information system strategies for doing the Total Quality Management of the Aviation industry. Moreover, in this report it also gives of the proper discussion of different techniques that are used to improve the quality management by doing proper use of Information strategies. Furthermore, it also discusses about different examples of the IS support techniques in doing the TQM implementation of Delta Airlines. Apart from this, it also focuses different Information strategies and select different processes of TQM implementation at Aviation Industry.
\end{abstract}

\section{Keywords}

Total Quality Management (TQM), Delta Airlines, TQM in Aviation Industry, Information System Strategy.

\section{INTRODUCTION}

Total Quality Management (TQM) is one kind of structured approach for management of the organization that improves the quality of the products and services [1]. Nowadays many airlines feel that for being remain in the competitive aviation market some kind of changes must be done.

For maintaining the nature, size and complexity of the Aviation Industry, there is always some issues arises, resistance and unforeseen circumstances in the maintenance sector. For overcome this issue, Information System(IS) support TQM in the aviation industry to provide services that is able to make the customer satisfy, this will cause repeat purchase hence increase the sales and profit of the organization. With the help of IS strategy for TQM in the activation industry is used for not only eliminates the defects of products and services but it also helpful for increasing the service speeds, product design, reduces costs and improve the quality of the work.

Out of the numerous aspects of customer services in the aviation industry, some of the most important that generally could be highly affected by the implementation of the information system are proficiency and productivity, rapid processing of the passengers, increased satisfaction of the customers, faster distribution of the information, etc. In this era of accelerated technical growth, customers become more information centric that could be distributed with more velocity. So different information regarding the seat booking, current reservation status, any updating information, etc. can be shared mush faster with the help of information system. Using the information system in the management and maintenance of the aviation industry several features could be achieved like updates of the data that would happen in real time, approximately 24/7 uptimes, interfaces that are userfriendly and dual-mode in nature, etc. Through these features the management of the materials and inventory becomes possible. Various tools and modules of the maintenance software also helps to optimize the cost associated with the operation, maintains the inventory control, etc.

This particular study mainly discusses how IS can contribute in achieving the objectives of Total Quality Management (TQM) in the aviation industry. Moreover, along to that it also discusses about various strategies that helps in terms of doing the implementation of TQM on aviation industry. Furthermore, in this study Delta Airlines are taken into consideration to give the proper understanding of the implementation of TQM.

In the following sections of the article various perspective of the implementation of the information system in the aviation industry has been highlighted, they include a descriptive analysis of the TQM, information system strategy of TQM in this industry, various previous researches in this field and different case studies.

\section{TQM IN AVIATION INDUSTRY}

Aviation Industry has succeeded around the world for offering a good quality of service that is highly affordable and safe. For achieving the maximum effectiveness, the organization should follow the international practices and also deploy an information system for maintaining the quality of services. TQM principles are helpful for brining the processes of the company under the statically control and a sustainable infrastructure of the implementation of the TQM [3]. Various activation industry implements TQM principles with Information System Strategy for achieving the goal of the organization [5]. TQM tool is regarded as a system that is capable of achieving important gain in the field of business performance. Apart from the quality of TQM that focus on the ability and quality for bringing the process of the enterprise under the statistical analysis. Many TQM tools acts as a highly effective and well structured methodology that make improvement in the process and product variation which further use for increasing the performance of the operation [15].

AvPro Software is a software tool that could be one of the best examples of the available information system usable for the quality management in the aviation industry. They have got various integrated module of software that is stand-alone in nature like the management of inventory, maintenance of the components, work orders, asset management, management of the employee and flight schedule, etc. A demo version of this software is also available that could be used as trial by the aviation industries.

\section{Delta Air Lines}

In the competitive environment the Delta Air Lines concentrate on the product and services along with the overall value chain that is helpful for increasing the satisfaction of the 
customer and profit of the company. The customer satisfaction is always achieved by providing high quality of product and services with the help of adopting a good price strategy [3].

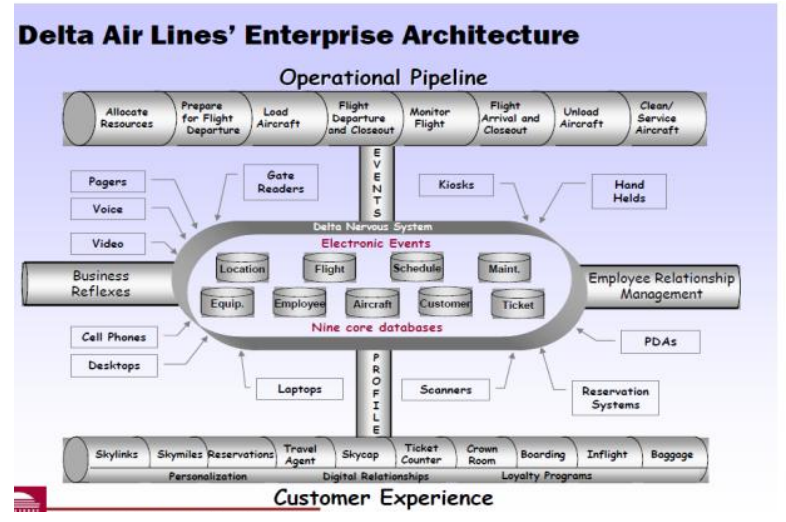

Figure 1: Enterprise Architecture of Delta Air Lines(Source: [5])

TQM of Delta Air Lines follows some strategy action that mainly focuses on the overall organization for giving the satisfaction to the customer regarding to its product and services with the help of all resources of the organization [7]. In the above mentioned figure, the management team discussed about four different core processes like operational pipelines, employee relationship management, customer experiences as well as different types of business reflexes [9]. Moreover, in the context of the quality management processes, the customer experiences helps to identify where it needs to improve their quality so that they can keep happy their customers [6]. Operational pipelines discusses about loading, unloading, moving as well as maintaining the planes. Moreover, employee relationship management encompasses of different processes like compensation, scheduling and development of high mobility workforces [11]. Apart from this, business reflexes helps to focus on the processes of doing pricing, scheduling as well as different financial processes.

In order to do the analysis of the Total Quality Management (TQM) of the Delta Airlines, it used different types of TQM tools that include Force Filed analysis, histograms etc. Moreover, in Delta Airlines it mainly do the use of Force Field Analysis which helps to identify both the driving and restraining forces of Delta Airlines which helps in doing the proper understanding of different Information System strategies used in Aviation industry.

\section{INFORMATION SYSTEM STRATEGY FOR TQM IN AVIATION INDUSTRY}

Information system provides greater reliability and scalability to quality of organizational product and services. Information system provides greater structure to total management system of quality structure that assures proper aviation maintenance over airline industry [12]. It requires to indentify proper concept and requires to determine issues in order to provide optimize result with implementation of proper aviation structure [4].

The rapid increase of interest of using TQM helps to do the improvement of different organizational performance in both the manufacturing sector as well as the service organization. Apart from that, to do the identification of different critical issues that helps in terms of determining the impacts of TQM discusses:

- Determination of different factors that helps to influence various TQM process used in Aviation industry.

- Classification of critical success factors of TQM that helps in terms of addressing the improvement of both the customer satisfaction and quality of Delta Airlines.

- Information strategies help to do the investigation of effective relationship between quality performances of Delta airlines and different TQM practices.

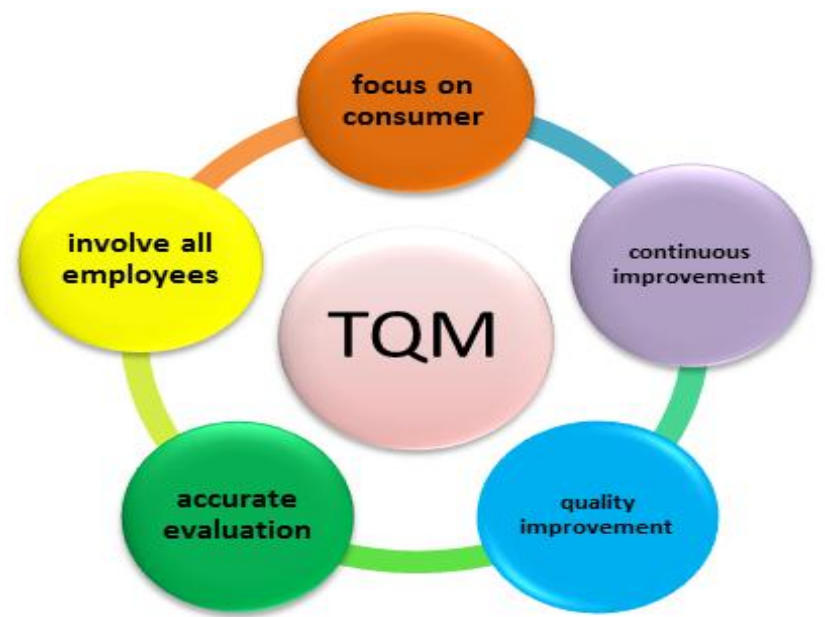

Figure 2: Information System Strategy for TQM inAviation Industry(Source: [6])

The various activities that necessitate the quality improvement in the Aviation Industry can be discussed as:

\section{Customer Experience}

Still one of the most ideal methods for focusing so as to fulfill quality change is acquired on clients' worries, and by realizing what those worries are through proprietor/client reviews. Much can be given by concentrate how your proprietor/client feels about your administration, your state of mind, and whether you would be prescribed to another proprietor/client. A few territories to study, and to fare thee well to give or respect, are recorded here. 


\begin{tabular}{|c|c|}
\hline $\begin{array}{l}\text { Safe working systems } \\
\text { Accident experience } \\
\text { Attitude } \\
\text { Professional } \\
\text { capability of the } \\
\text { undertaking chief, } \\
\text { director, and venture } \\
\text { engineers } \\
\text { Technical fitness of } \\
\text { the work power } \\
\text { Overall } \\
\text { responsiveness to } \\
\text { proprietor/customer } \\
\text { requests }\end{array}$ & $\begin{array}{ll}\text { - } & \begin{array}{l}\text { Degree of } \\
\text { interchanges }\end{array} \\
\text { - } & \text { Planning } \\
\text { - } & \begin{array}{l}\text { Administrative } \\
\text { strategies }\end{array} \\
\text { - } & \begin{array}{l}\text { Appearance and } \\
\text { behavior of the work } \\
\text { power }\end{array} \\
\text { - } & \text { Condition of hardware } \\
\text { - } & \begin{array}{l}\text { Coordination and } \\
\text { supervision of } \\
\text { subcontractors }\end{array} \\
\text { - } & \begin{array}{l}\text { Appearance of the } \\
\text { jobsite }\end{array}\end{array}$ \\
\hline
\end{tabular}

It is identifying that qualified trainers is also key issues in aviation system. Lack of proper experienced and quality trainer information stem over quality system deploying. It needs to selects proper trainer as well as experienced person for trained aviations staffs. Aircraft system knows proper technicians system theory as well as able to executes and interpret tests, maintains proper organizational elements.

\section{Management}

Keeping in mind the end goal to direct an investigation of the interior procedures inside of the organization, the accompanying steps ought to be connected to the inner procedures inside of an organization.

- List a few of the interior proprietors/clients inside of the Industry

- Choose one of these proprietors/clients to concentrate on for the use of this system

- Determine the Outputs (items, administrations, data) that must be given to this interior proprietor/client

- Determine the work Processes that the business makes use of to create these Outputs

- Learn how the client's desires are met and how fulfillment is evaluated

\section{Maintenance}

The effective TQM Company gives preparing to representatives in the request delineated in the figure underneath. The preparation system must start with upper administration, and after that preparation must be accommodated the remaining administration, and the in-house mentors and facilitators. It can't be sufficiently stressed that if upper administration is not prepared and is not a practical, obvious member from the earliest starting point, then the system won't survive.

\section{Communication Service}

There are several issues detects that prevents aviation industry from various information system and procedures as like communication service. Communication problem or issues are the major key issues in aviation industry that requires communicating managers, manufacturer, pilots, with public, and others. Proper communication as well as qualitative standards use in communication to decrease complicated systems.
Role of IS to improve the customer experience: the aviation industry, just like any other industry, if becomes successful to deploy the information system in their regular process of customer handling, then customers would automatically start approaching them since they would find new means of communication instead of the older and conventional ones. With the help of IS, this industry could ensure the customers can get access to the information required in a very convenient manner in all these channels. Thus the customers would also be able to distinguish a particular aviation industry form others distinctly. Hence there is huge scope and opportunities for the airline industry to make use of IS in their system. Some of the examples are launching of passes through mobile boarding in Etihad Airways, launch of an exclusive app for iPad by UAE, etc.

Role of IS to improve the management: the infusion of management system in the aviation industry would impose several benefits to the system such as; it can save the cost significantly since performance of the equipments would be improved considerably. Apart from that, enhanced availability of the management that would help the management focus on additional activities could be achieved. This is important as the data would be automatically gathered by the real time system. Also, using the automatic alerts and with the provision of the scope of status monitoring the asset efficiency will be increased. Above all, the team of management would be able to plan the activities of maintenance with more adept.

Role of IS to improve the maintenance: using the information system in the aviation system, the facility regarding the equipments would also be automated with enhanced flexibility. This would also help to build fresh system for the regulation of the servicing. Above all this is expected to enhance the velocity of the communication and exchange of information as well along with the mobilization of little community of entities.

Role of IS to improve communication services: communication services can be significantly improved using IS characteristics such as implementing efficient communication mediums that can facilitate easy and quick interfaces to link the communicators. Furthermore, more providing better information about the different organizational levels and their corresponding activities can also be achieved by IS services.

To determine the role of the Information Strategy to implement TQM in Aviation Industries, it is needed to establish the connection between maintenance performance and TQM. Moreover, IS also helps to identify different issues and concepts that helps to optimize the processes with the help of the implementation of proper management. Apart from that, IS strategies also used in doing the determination of communication issues, training issues and different maintenance issues. It also helps to improve different quality controlling techniques for Aviation Industries.

\section{LITERATURE REVIEW}

TQM is an approach or methodology that use to achieve high quality and sustainable quality products and services that focus on improvement of maintenance and continuous process that detects prevention or blocks each of organization level and provide qualitative and effective products and services to business world. Quality management and better understanding principles derives standard quality management 
[14]. TQM is a process that improves aviation industry continuously and improves quality with management philosophy that accomplishes customers or clients for their satisfaction. Proper principle and management increase aviation industry quality as well as reduce extensible cost [2].

Information System supports TQM structure in the aviation industry to deliver services that makes able to customer satisfy. This would cause repeat purchase of quality system. Proper communication as well as qualitative standards use in communication to decrease complicated systems. It is identifying that qualified trainers is also key issues in aviation system [10]. Purpose of the Delta Air Lines is to improve quality of the organizational service.

A contextual investigation of a carrier which is an individual from Star Alliance gathering mirrors that the aircraft needs to keep up elevated amounts of adaptability to confront new difficulties from contenders around the globe, and to distinguish and make new administrations to enhance consumer loyalty and decrease costs. The increment in traveller and things volumes, in addition to the improvement of worldwide partnerships and double exchange flights, all make huge difficulties for carriers and airplane terminals. This is particularly valid for a carrier taking care of more than 2 billion travellers for each year. This puts an additional burden on the current things taking care of framework, which depends on a maturing Barcode framework. The aircraft, in this way, requires a very proficient system to handle the expanding travellers and stuff volumes, and

RFID innovation has drawn the consideration of the aircraft. The vital significance of RFID applications can't be thought little of and the progression of RFID makes open doors for new and creative administrations gave through the RFID foundation. RFID is required to radically affect the association's vital administration. One of the key needs for the aircraft is to offer brilliant administrations to its customer base and, furthermore, the carrier organization seems to target chiefly the premium portion of the business sector. The real point of preference of focusing on the top end fragment of the business sector is that it gives the carriers the chance to expand income and benefit era, a key component in the exceptionally aggressive and not extremely productive aircraft industry. As of late the organization began a RFID venture with two principle destinations:

- To guarantee better administrations, particularly regarding administration conveyance. Change in stuff following and things conveyance has been distinguished as key business driver.

- To start another Frequent Flyer Program (FFP) test venture for premium individuals taking into account RFID innovation, with the primary point of giving tweaked and customized administrative service.

By centring a company's RFID system on client confronting exercises, a firm can utilize the innovation to change its premise of rivalry from an effectiveness arranged procedure to one where RFID has more vital ramifications, for example, in giving the establishment to new items or administrations, or by giving the foundation to improve clients' worth observations keeping in mind the end goal to fortify client dependability. The extra usefulness of RFID permits data to be changed at diverse focuses in the aircraft framework. This makes it conceivable to hold sacks for security checking and discharge them for stacking when checked, gave the RFID framework is connected to the things compromise frameworks. Also, RFID will be utilized to track traveller progress through air terminals, decreasing the quantity of travellers arriving late at the door, and in doing as such guaranteeing that planes depart on time.

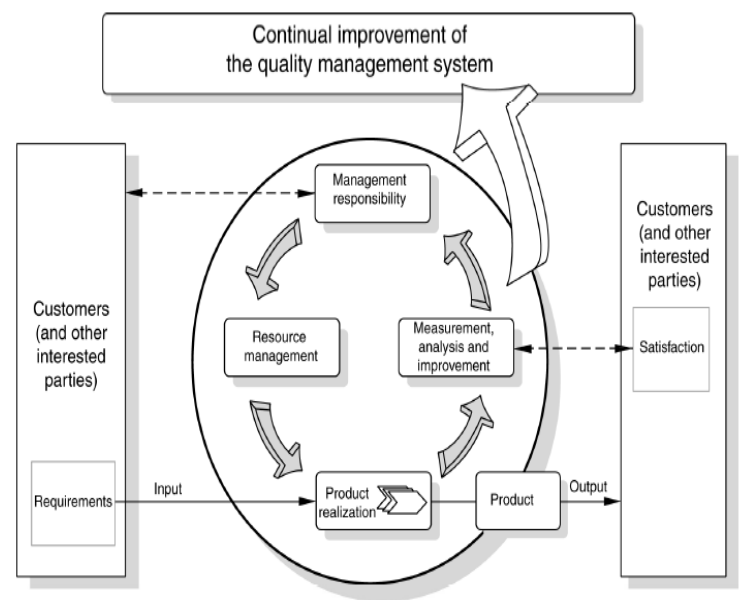

Figure 3: Improvement of Quality Management System Using IS Strategy(Source: [13])

In the qualitative system environment, competitive environment of the Delta Air Lines properly concentrate on the various informational product and services along with the all grade value chain that makes more helpful for increasing the satisfaction of the customer and profit of the company [16]. Hence, increase the sales and profit of the organization provides or use to delivers more quality to customers. It is derives that qualified trainers is also key issues in aviation system.

Lack of proper experienced and quality trainer information stem over quality system deploying. It needs to selects proper trainer as well as experienced person for trained aviations staffs. The customer satisfaction can achieved from providing high quality structural information and product and services with the help of adopting a good organization price strategy of proper product that can delivers efficiency and flexibility to the system organization [8].

There are various systematic activation industry implements quality strategy and principles with information system for achieving the goal of organization. Flexibility and quality of systems are capable to achieving important gain in the field of business performance. Derived and adequate structured methodology makes organizational improvement in the process and product variation, which further makes useful for increasing the performance of the aviation system operation [13].

Thomas L. Seamster conducted a study in this field that entails with operational data administration that is at an intersection as it sheds the remaining remnants of its paperbased procedures and travels through the uncharted space of electronic information forms. The last result is not yet in full concentrate, but rather genuine advancement has been made in the move to electronic archives furnishing the flying business with a reasonable heading.

Another research was conducted where the main focus was on the crossing point of the ranges of aeronautics and administration of data frameworks is rare. Air terminals, like never before need to adjust their data frameworks to pick up an upper hand and turn out to be more proficient in their 
operations. A legitimate arrangement is an essential to frameworks arrangement. The reason for this paper is to give portrayals of a portion of the airplane terminal administration data frameworks, associations with or interoperability with different frameworks, and the key uses and clients of every framework.

All these previous studies helped this project a lot in terms of giving a proper guide to the recent trend of development.

\section{CASE STUDY}

The example of one of Information System support in TQM implementations is APOLLO (USA) Airline Reservation System. APOLLO (USA) Airline Reservation System is helpful for increasing the efficiency which is acts as a barrier to the entry for new competition in the industry and also helpful for discouraging the organizations that are already present in the market [7]. APOLLO enhance the effectiveness of the airline of its organization by increasing the investment amount or the by increasing the complexity of the required technology for competing in the marketplace along with discourage the organizations that are already present in the industry and acts as a barrier to the external organization from entering in the industry [14].

This Information System support TQM by enabling the organization for building a strategic IT platform that is giving permission for taking advantage of the strategic opportunities. This includes acquiring software and hardware, hiring specialist of information system, developing telecommunication networks and hiring training end user.

An organization can leverage investment in the information system by creating new product and services. This information system supports the TQM in the aviation industry. The attributes and features involved by this information system in the field of TQM are given below:
1. Performance
2. Reliability
3. Responsiveness
4. Durability
5. Reputation
6. Aesthetics

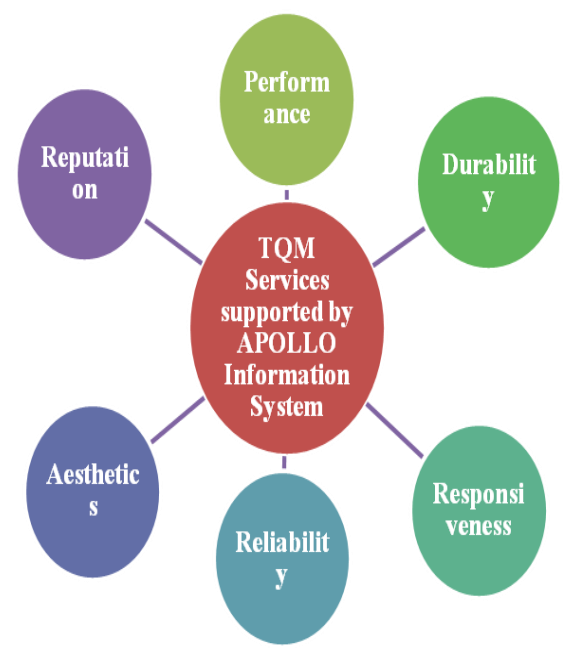

Figure 4: TQM Services supported by APOLLO (USA) Airline Reservation System(Source: [6])
This Information System is a strategy requirement for delivery and development of agile product. This information system provides the required information by the people for supporting the agile operation along with the information that are build into product and services of the particular organization [9]. According to several authors, APOLLO helps IS to improve different elements of total quality that include: customer focus, continuing improvement systems, purposes unity, quality obsessions and different scientific approaches [10]. Moreover, it also discusses about different elements of TQM that helps to understand the quality that can be adaptable in environment. In order to deduce the quality of IS it develops and organizational wide culture and also helps to keep the identification and changes of works.

\section{Enhancing Business Processes:}

Interests in data innovation can make a company's operational procedures considerably more productive and its administrative procedures a great deal more powerful. By making such upgrades to its business forms a firm may have the capacity to:

1. Dramatically cut expenses

2. Improve the quality and client administration

3. Develop imaginative items for new markets

\section{Advancing Business Innovation}

Interests in data frameworks innovation can bring about the improvement of new items, administrations, and procedures. This can:

1. Make new business opportunities

2. Empower a firm to enter new markets

3. Empower a firm to go into new market fragments of existing markets.

\section{Lock In Customers and Suppliers}

Interests in data innovation can likewise permit a business to secure clients and suppliers (and lock out contenders) by building important new associations with them. This can be expert by:

1. Deters both clients and suppliers from deserting a firm for its rivals or threatening a firm into tolerating less gainful connections.

2. Offer better-quality administration to clients permits an organization to separate themselves from their rivals.

3. Create between hierarchical data frameworks in which information transfers organizes electronically interface the terminals and PCs of organizations with their clients and suppliers, bringing about new business collusions and associations.

\section{Making Switching Costs}

A noteworthy accentuation in vital data frameworks is to incorporate exchanging expenses with the connections between a firm and its clients or suppliers. That is, interests in data frameworks innovation can make clients or suppliers reliant on the proceeded with utilization of inventive, commonly helpful between authoritative data frameworks. At that point, they get to be hesitant to pay the expense in time, cash, exertion, and impairment that it would take to change to an association's rivals. Case: APOLLO (USA) aircraft reservation framework, and GEMNI (CAN) carrier reservation framework. 


\section{CONCLUSION}

From this paper it can be concluded that Information System supports Total Quality Management (TQM) in the activation industry. The strategy of the Information System is formulated for the TQM in the activation industry. The TQM process in the aviation industry with the help of information system in Delta Air Lines is described in detail. The literature review that is mentioned in this paper discusses the research work in this field and it is also helpful for relating this research with the previous done work. The case study of APOLLO (USA) Airline Reservation System, which is information System Support for implementing TQM in the airline industry is shows how IS have an important role in the TQM in the aviation industry.

It is demonstrated that there are various advantages driven by executing TQM standards as far as consumer loyalty, operational adequacy and representative fulfillment. Avionics Industries must take upkeep issues moderately intense as it is a chief determinant of their persistent presence in the quickly changing Aviation Market. In the carrier's upkeep area, the essential way of TQM is to give administrations which will make clients fulfilled. This thus would build the quantity of clients and notoriety sequentially, along these lines expanding deals and gainfulness of the association.

\section{ACKNOWLEDGEMENTS}

I would like to take this opportunity to thank my supervisor for the constant guidance and support provided to me during the process of this research. This would not have been possible without the valuable guidance of my professors, peers and all the people who have contributed to this enriching experience.

\section{REFERENCES}

[1] Q. Lo and K. Chai, "Quantitative analysis of quality management literature published in total quality management and business excellence (19962010)", Total Quality Management \& Business Excellence, vol. 23, no. 5-6, pp. 629-651, 2012.

[2] M. A. Khan, "Evaluating the Deming Management Model of Total Quality in Telecommunication Industry in Pakistan -- An Empirical Study.” Int. J. Bus. Manage. vol. 5, no. 9, pp. 46-59, 2010.

[3] T. Green, "TQM and organizational culture: How do they link?" Total Quality Management \& Business Excellence, vol. 23, no. 2, pp. 141-157, 2012.

[4] M. Al-Zoubi, "Generating benchmarking indicators for employee job satisfaction", Total Quality Management \& Business Excellence, vol. 23, no. 1, pp. 27-44, 2012.
[5] A. Ueno, "Which HRM practices contribute to service culture?", Total Quality Management \& Business Excellence, vol. 23, no. 11-12, pp. 1227-1239, 2012.

[6] M. Elg and B. Kollberg, "Conditions for reporting performance measurement", Total Quality Management \& Business Excellence, vol. 23, no. 1, pp. 63-77, 2012.

[7] M. Linz, "Scenarios for the aviation industry: A Delphibased analysis for 2025," J. Air Transp. Manag., vol. 22, pp. $28-35,2012$

[8] Osman and H. Ali, "Total Quality Management in the Malaysian Automobile Industry," Total Qual. Manag. Malaysian Automob. Ind., no. January, pp. 203-209, 2009.

[9] S. Shan, Q. Zhao, and F. Hua, "Impact of quality management practices on the knowledge creation process: The Chinese aviation firm perspective,' Comput. Ind. Eng., vol. 64, no. 1, pp. 211-223, 2013.

[10] C. a. Benavides-Velasco, C. Quintana-García, and M Marchante-Lara, "Total quality management, corporate social responsibility and performance in the hotel industry,” Int. J. Hosp. Manag., vol. 41, pp. 77-87, 2014.

[11] Z. Wen and Y. Liu, "Applications of Prognostics and Health Management in aviation industry," in Prognostics and System Health Management Conference (PHMShenzhen), 2011, 2011, pp. 1-5.

[12] M. Arif, A. Gupta, and A. Williams, "Customer service in the aviation industry - An exploratory analysis of UAE airports," J. Air Transp. Manag., vol. 32, pp. 1-7, 2013.

[13] T. Broekel and R. Boschma, "Knowledge networks in the Dutch aviation industry: The proximity paradox," J. Econ. Geogr., vol. 12, no. 2, pp. 409-433, 2012.

[14] Z. S. Kahreh, A. Shirmohammadi, and M. S. Kahreh, "Explanatory Study Towards Analysis the Relationship between Total Quality Management and Knowledge Management," Procedia - Soc. Behav. Sci., vol. 109, pp. 600-604, 2014

[15] Harrington, H., Voehl, F. and Wiggin, H. (2012). Applying TQM to the construction industry. The TQM Journal, 24(4), pp.352-362.

[16] Talib, F., Rahman, Z., Qureshi, M. and Siddiqui, J. (2011). Total quality management and service quality: an exploratory study of quality management practices and barriers in service industry. International Journal of Services and Operations Management, 10(1), p.94 